\title{
BMJ Open Transformation of the Tanzania medical stores department through global fund support: an impact assessment study
}

\author{
Patrick Githendu, ${ }^{1}$ Linden Morrison, ${ }^{1}$ Rosemary Silaa, ${ }^{2}$ Sai Pothapregada, ${ }^{1}$ \\ Sarah Asiimwe, ${ }^{1}$ Rafiu Idris, ${ }^{1}$ Tatjana Peterson, ${ }^{1}$ Emma Davidson, ${ }^{2}$ \\ Abaleng Lesego, ${ }^{3}$ Neema Mwale, ${ }^{4}$ Sako Mayrick Mwakalobo, ${ }^{4}$ \\ Laurean Rugambwa Bwanakunu, ${ }^{4}$ Tom Achoki (i) ${ }^{3,5}$
}

To cite: Githendu P, Morrison L, Silaa R, et al. Transformation of the Tanzania medical stores department through global fund support: an impact assessment study. BMJ Open 2020;10:e040276. doi:10.1136/ bmjopen-2020-040276

- Prepublication history and additional material for this paper are available online. To view these files, please visit the journal online (http://dx.doi. org/10.1136/bmjopen-2020040276).

Received 08 May 2020 Revised 05 0ctober 2020 Accepted 15 October 2020

Check for updates

(C) Author(s) (or their employer(s)) 2020. Re-use permitted under CC BY-NC. No commercial re-use. See rights and permissions. Published by BMJ.

${ }^{1}$ The Global Fund to Fight AIDS Tuberculosis and Malaria, Grand-Saconnex, Genève,

Switzerland

${ }^{2}$ Independent Consultants, Dar es Salaam, Tanzania, United Republic of

${ }^{3}$ Africa Institute for Health Policy Foundation, Nairobi, Kenya

${ }^{4}$ Tanzania Medical Stores

Department, Dar es Salaam,

Tanzania, United Republic of

${ }^{5}$ School of Health Systems and

Public Health, University of

Pretoria, Pretoria, South Africa

Correspondence to

Dr Tom Achoki;

tachoki@sloan.mit.edu

\section{ABSTRACT}

Background The Tanzania government sought support from The Global Fund to Fight AIDs, Tuberculosis and Malaria to reform its Medical Stores Department, with the aim of improving performance. The study sought to assess the impact of the reforms and document the lessons learnt.

Methods Quantitative and qualitative research methods were applied to assess the impact of the reforms. The quantitative part entailed a review of operational and financial data covering the period before and after the implementation of the reforms. Interrupted time series analysis was used to determine the change in average availability of essential health commodities at health zones. Qualitative data were collected through 41 key informant interviews. Participants were identified through stakeholder mapping, purposive and snowballing sampling techniques and responses were analysed through thematic content analysis.

Results Availability of essential health commodities increased significantly by $12.6 \%$ (95\% Cl $9.6 \%$ to $15.6 \%)$ after the reforms and continued to increase on a monthly basis by $0.2 \%(95 \% \mathrm{Cl} 0.0 \%$ to $0.3 \%)$ relative to the preintervention trend. Sales increased by $56.6 \%$ while the cost of goods sold increased by $88.6 \%$ between 2014/2015 and 2017/2018. Surplus income increased by $56.4 \%$ between $2014 / 2015$ and $2017 / 2018$ with reductions in rent and fuel expenditure. There was consensus among study participants that the reforms were instrumental in improving performance of the Medical Stores Department.

Conclusion Positive results were realised through the reforms. However, despite the progress, there were risks such as the increasing government receivable that could jeopardise the sustainability of the gains. Therefore, multistakeholder efforts are necessary to make progress and expand public health.

\section{INTRODUCTION}

The World Health Organization (WHO) has clearly elaborated the six core functions of a competent health system. These include; (1) ensuring adequate health financing; (2) development and deployment of human resources for health; (3) effective service
Strengths and limitations of this study

- This study used mixed methods to comprehensively assess the impact of reforms at a national medical store department through a donor funded initiative.

- The lessons learnt are applicable to many lowincome and middle-income countries that are grappling with challenges in the procurement and supply of medicines and other health commodities.

- Our study covered a limited period of observation and relied on secondary programmatic data and key informant interviews that are prone to various forms of bias and could lead to spurious conclusions.

delivery; (4) promoting access to essential medicines and other health technologies; (5) collection, analysis and utilisation of critical health information and (6) effective leadership and governance. For impactful delivery of health services, all the six components must work in tandem to produce the desired health outcomes. ${ }^{12}$

The Tanzanian government has clearly recognised the critical role that access to safe and high-quality medicines and other health technologies play in ensuring optimal population health outcomes. ${ }^{3}$ To this end, the Medical Stores Department (MSD) was set up as an autonomous department of the Ministry of Health, Community Development, Gender, Elderly and Children (MoHCDGEC) through an Act of Parliament in 1994. Its overarching mandate is to procure, store and distribute medicines and supplies to all public health facilities in the country. ${ }^{3-8}$ Since its founding, MSD registered steady growth in its business operations, but started to flounder around the year 2006, resulting in frequent stock-outs of essential medicines and other supplies at public health facilities. ${ }^{9}$ To illustrate, a survey conducted in 2011 across a sample of HIV/ AIDS care and treatment clinics in Tanzania, 
revealed that stock-out of antiretroviral drugs was reported in up to $80 \%$ of the sites, during the 12 months preceding the survey. ${ }^{10}$ Therefore, it was evident that the MSD was facing several challenges that hindered its effective functioning and delivery on its mandate. ${ }^{911}$

As a result, the Tanzania government sought support of The Global Fund to Fight AIDs, Tuberculosis and Malaria (Global Fund), which commissioned a detailed assessment to comprehensively understand the challenges facing MSD and their underlying causes. This formed the basis of the strategic reforms that were initiated at MSD with the support of Global Fund, aimed at transforming the organisation into an effectively functioning autonomous department within the MoHCDGEC..$^{911-14}$

There is evidence from the literature that procurement and supply-chain systems for medicines and health commodities in many low-income and middle-income countries are faced with end to end challenges. ${ }^{1516}$ These include, problems related to forecasting and quantification; storage, inventory management and distribution; quality assurance, information management and reporting, among others. For instance, Cameron et $\mathrm{al}^{17}$ report that average availability of generic medicines in the public sector across $\mathrm{WHO}$ regions was low, ranging from $29.4 \%$ to $54.4 \%$. Purchasing and distribution inefficiencies and price markups leading to significant unaffordability, particularly in the private sector were cited as some of the key bottlenecks. Godman $e t a l^{18}$ identify access and affordability challenges facing type 1 diabetes mellitus patients in Africa despite efforts to make progress. Bigdeli $e t a l^{19}$ and Ewen $e t a l^{20}$ further support this observation, highlighting the fact that procurement and supply-chain challenges contribute significantly to low access to essential medicines and general inefficiency of health systems in many countries. Citing examples from Kenya and Tanzania, Mackintosh $e t a l^{21}$ further emphasise that fragmented procurement and distribution systems have negative implications on overall population access to high quality medicines and related health outcomes.

It is based on these facts that the Global Fund Strategy of 2017-2022, clearly acknowledges that building resilient and sustainable health systems (including procurement and supply-chain components) are central to progress towards universal health coverage and acceleration to end the epidemics associated with HIV/AIDS, Tuberculosis and Malaria. ${ }^{22}$ To highlight the significance of this strategy, it is estimated that approximately $40 \%$ of the Global Fund support going to countries for various disease programmes, is used for procurement and supplychain management of health products. ${ }^{15} 1622$

Therefore, given the importance of procurement and supply-chain systems in the overall performance of health systems, a thorough examination of the Tanzania MSD strategic transformation effort would be instructive. The lessons would be particularly relevant to various health system stakeholders, including donors and implementing organisations that are keen to align their funding and implementation priorities, in order to sustainably strengthen health systems. Our article aims to assess the impact of the MSD reforms and document the experiences and lessons learnt. More specifically, we focus on the operational and financial performance of MSD, which is a reflection on the overall institutional management practices.

\section{METHODS}

This study employed both quantitative and qualitative research methods in assessing the impact of the reforms implemented at MSD. The quantitative section focused on trend analysis of priority indicators derived from financial statements and operational reports at MSD. Meanwhile, the qualitative approach entailed key informant interviews (KII) that collected and analysed views from various levels of the healthcare system, in order to give perspective to the observed trends. The overall duration of the study was from July 2019 to September 2019.

\section{Study setting}

The Tanzania health system follows a decentralised model, from village dispensaries and community-based health facilities at the ward level (under the responsibility of local government authorities), to district, regional and national-level hospitals. Under this system, the district is mandated to plan, implement, monitor and evaluate health services. Primary healthcare services are provided through dispensaries at the ward level, catering for three to five villages with an average population of 10000 . The health centre is the referral level for the dispensary, covering a population of approximately 50000 , and provides a slightly expanded range of services, including inpatient care. Next is the district hospital, which provides services to an average of 250000 people. ${ }^{4-8}$

Medicines in Tanzania are supplied to patients in public health facilities on a cost-sharing basis. Patients holding the national health insurance card, or a council card reserved for rural areas, usually cover about $50 \%$ of the cost. For the poorest in society, children under 5, pregnant women and people over 60 years, the current policy is to provide medical services and medicines for free. Despite the coverage, for most of the population, paying $50 \%$ of the price out of pocket still presents a significant barrier to accessing the care they need. ${ }^{3-9}$

MSD is responsible for the procurement, storage and distribution of health commodities to an estimated 5940 health facilities across the country. ${ }^{79}$ To enhance its efficiency and national coverage, it has a network of eight zonal stores and two sales points that service health facilities across the different regions in the country. The zonal stores are organised into strategic business units that are independently managed and have clear performance targets aimed at meeting the needs of all health facilities within their specific region. To facilitate efficient operations and expand coverage, there are two sales points in the Kagera and Tanga regions under the supervision of their respective zonal stores. Furthermore, within five 
zones, there are seven community outlets where members of the public can directly purchase essential medicines. ${ }^{9}$

In terms of governance, MSD has a Board of Trustees (Board) as its highest decision-making body that governs and sets the strategic direction. It is composed of nine members appointed for a 3-year term by the government. The President of the country appoints the Chairman of the Board, while the Minister of MoHCDGEC appoints the rest of the eight members. The Director General, who is also appointed by the President of the country serves as the Secretary to the Board and is responsible for the day-to-day management of the organisation. To effectively support their oversight role, the Board operates through three committees, namely; Audit and Risk Management Committee, Technical Services Committee as well as Finance and Administration Committee. ${ }^{9}$

Operationally, MSD's procurement function is centralised at the headquarters in Dar es Salaam, which serves as the central warehouse and distribution hub to the respective zones and sales points in the country. ${ }^{9-11}$ Medicines and supplies used in the public health facilities are purchased with government funding that is deposited directly into MSD accounts, as specified in the Procurement Act of 2004, and drawn according to the health facilities needs. ${ }^{9} 1314$

\section{Intervention}

In 2015, the Tanzania government sought assistance from the Global Fund, to undertake a strategic review to understand the main challenges facing MSD that had led to erosion of working capital and subsequently triggered a cycle of operational deficiencies. Subsequently, a set of strategic reforms were recommended aimed at improving the overall performance and long-term sustainability of MSD. ${ }^{912} 13$

Briefly, the reforms focused on aspects of MSD governance, operational and financial performance. In terms of governance, the Global Fund supported the establishment of an independent Board, with expertise to provide functional leadership and oversight on the core areas of MSD operations. The governance reforms also facilitated the creation of the Strategic Management Office (SMO), in August 2016, which assumed the responsibility of coordinating, monitoring and evaluating various aspects of implementation towards the envisaged strategic reform objectives. More specifically, this entailed regular training of staff, building technical capacity and development of standard operating procedures and reporting tools, to improve management practices within the organisation. Initially, the SMO activities were supported through Global Fund sponsored external consultancy assignments, but these were gradually transitioned inhouse as the overall technical capacity of the SMO strengthened to carry out its mandate. Further, the reforms included the integration of supply-chain training modules into the national curriculum of the health workforce in Tanzania, as a sustainability measure. ${ }^{912-14}$
In terms of operational and financial performance, Global Fund support was mainly focused on the recapitalisation of MSD, through fleet improvements at MSD, which started from January 2017 and continued for the rest of the year. As per the recommendations of a study financed by the Global Fund, a modern fleet of 181 vehicles was procured, to allow for direct delivery of health commodities from zonal stores to respective health facilities. ${ }^{9}$ In addition, steady efforts were made towards a comprehensive logistic system redesign, aimed at enhancing efficiencies in the procurement and distribution of medicines and health commodities in the country. ${ }^{912} 13$ For instance, at the time of this study, measures were underway to standardise laboratory systems across the country, in order to benefit from the economies of scale in the procurement of equipment and consumables as well as maintenance.

Another critical area of Global Fund support was equipping MSD with modern storage capacity. The central warehouse, with an estimated storage capacity of 20335 $\mathrm{m}^{2}$ was built with support from the US Government and the Global Fund. Additionally, zonal stores across the country were supported to acquire modern warehouses that greatly enhanced their storage capacity. As a result of the expanded holding capacity, MSD increased the portfolio of items it routinely tracked from 135 to $312 .{ }^{9} 1314$

To empower MSD with robust information management systems and capacity to optimise on business processes, an enterprise resource planning software, EPICOR, was procured and operationalised through US Government assistance. Additional upgrades of EPICOR were made through the Global Fund support in the ensuing periods, to ensure optimal data collection and utilisation to support MSD operations. Further, in order to ensure financial sustainability of operations, the Global Fund consistently paid an additional $6 \%$ of the cost of the medicines and other health commodities it distributes through the MSD channels, to cover the handling and distribution costs. This service charge forms a significant source of revenues for MSD to finance its operations. ${ }^{911-14}$

\section{Phase 1: quantitative research}

The quantitative component of the study entailed a detailed analysis of the operational and financial indicators, reported by MSD covering a period from financial year 2015-2019, with the strategic reform intervention starting on August 2016. Our analysis examined trends of priority indicators shown on table 1 , before and after the implementation of the reform, in order to track the resultant changes in MSD operations and financial position.

To determine the impact of the intervention on the availability of essential health commodities, we applied interrupted time series analysis (ITSA), using a userwritten STATA command of 'ITSA' which uses OLS regression-based models specifically designed for time series data. Our model of choice was Newey-West, which is suited to handle autocorrelation in addition to possible heteroskedasticity. ${ }^{23}$ 
Table 1 Definition of MSD performance indicators

\begin{tabular}{lll}
\hline Indicator & Definition & Primary source \\
\hline Stock Availability & This indicator measures the percentage of availability of a specific product or \\
products that the site is experienced to provide at any point within a defined \\
period of time. For all items listed as tracers, this indicator measures the \\
percentage of days when items at Central /Zonal warehouse have been at \\
stock level above safety stock; which is 1 month of stock at any time during \\
the month.
\end{tabular}

Order fill rate

The rate at which customer orders can be filled from existing zonal inventory

EPICOR within the parameters of the order request. This indicator measures the percentage of items ordered that are received to determine whether an order is filled in the correct quantities with the correct products. This indicator can be used to measure individual products (line fill rate) or for an entire order. The purpose here is to determine how effective MSD is satisfying customer orders. A higher fill rate is usually equated to higher customer satisfaction

$\begin{array}{ll}\begin{array}{ll}\text { Integrated logistics system } \\ \text { (ILS) delivery coverage }\end{array} & \begin{array}{l}\text { This indicator measures the percentage of (ILS) orders shipments delivered on } \\ \text { time at primary healthcare facilities at the set and agreed delivery schedule (ie, }\end{array} \\ \text { dates) during a defined period of time }\end{array}$

Sales /revenues Revenue, often referred to as sales, is the income received from normal business operations and other business activities of MSD. For MSD, this

Financial statements is indicative of the volume of health commodities distributed and their corresponding monetary value. For MSD, preference is to calculate sales on a quarterly and annually basis.

\begin{tabular}{ll}
$\begin{array}{l}\text { Cost of goods sold } \\
\text { Gross margin }\end{array}$ & $\begin{array}{l}\text { Cost of goods sold includes all of the costs directly related to the procurement } \\
\text { of the medicines and health commodities distributed by MSD. For MSD, } \\
\text { preference is to calculate the cost of goods sold on a quarterly and annually } \\
\text { basis. }\end{array}$ \\
\hline Gross margin is the difference between the revenue and the cost of goods \\
sold, for a specific period of time.
\end{tabular}

MSD, Medical Stores Department.

We set the time point of the intervention at December 2016 in our primary analysis, which was the midpoint of the intervention component aimed at setting up the $\mathrm{SMO}$, and the beginning of the fleet improvements at MSD. Our analysis assumed a 2-month potential time lag partly because according to conversations with in-country experts, this is the time it normally took for projects of this nature to be planned and executed within the health system in Tanzania.

The regression model used in ITSA is represented by the equation ${ }^{23}$ :

$$
Y_{t}=\beta_{0}+\beta_{1} T_{t}+\beta_{2} X_{t}+\beta_{3} X_{t} T_{t}+e_{t}
$$

Where,
- $\mathrm{Y}_{\mathrm{t}}$ is the aggregated outcome variable measured at each equally spaced time point $t$.

- $\mathrm{T}_{\mathrm{t}}$ is the time since the start of the study.

- $\mathrm{X}_{\mathrm{t}}$ is a dummy variable representing the intervention (preintervention periods 0 , otherwise 1 ).

- $\mathrm{X}_{\mathrm{t}} \mathrm{T}_{\mathrm{t}}$ is an interaction term, between $\mathrm{X}$ and $\mathrm{T}$.

- $\mathrm{e}_{\mathrm{t}}$ is the estimate of the error.

- $\beta_{0}$ represents the intercept or baseline of the outcome variable.

- $\beta_{1}$ is the slope or trajectory of the outcome variable until the introduction of the intervention.

- $\beta_{2}$ represents the change in the level of the outcome that occurs in the period immediately following the 
introduction of the intervention (compared with the counterfactual).

- $\beta_{3}$ represents the difference between preintervention and postintervention slopes of the outcome.

To adjust for seasonality and other long-term data trends, we fitted the data on availability of health commodities to a cubic spline over time to cover the full time series. The predicted results from the cubic spline are shown in online supplemental appendix 1. We then analysed the predicted values using the same ITSA model described above. ${ }^{24}$ Additionally, to assess potential different time lags regarding the impact of the reform, we performed sensitivity analyses of the ITSA with various interrupted time periods: from October 2016 to February 2017 (results not shown), besides the primary ITSA analysis, and the results were robust. All $\mathrm{p}$ values were two sided, and $\mathrm{p}<0.05$ was considered statistically significant. Data were analysed using STATA/MP V.16.0 (StataCorp).

Other operational indicators were extracted from the EPICOR generated reports and trends assessed over time. Financial data were extracted from the audited MSD financial statements, reported annually on a period covering July 1 to June 30 . These data were subject to standard financial analysis and trends assessed to determine changes over time. Relevant ratios to determine financial performance were calculated using standard financial analysis techniques.

\section{Phase 2: qualitative research}

Phase 2 of the study applied qualitative research methods. This part of the study was conducted between August and September 2019 and collected views of key informants who were knowledgeable and intimately involved in the reform initiative at MSD.

\section{Sampling and data collection}

Participants were selected through non-probability sampling procedures termed purposive sampling and supplemented through snowballing until we reached information saturation. ${ }^{25} 26$ In our case, purposive sampling was a judgement selection based on the participant's knowledge and involvement in the MSD reform through Global Fund support.

In order to guide our initial judgement in the identification and selection of study participants, we first undertook a comprehensive desk review mapping out the different stakeholders involved in the strategic reforms at MSD. A representative list of 17 organisations, including the public, private, development partners and civil society organisations were drawn to ensure that views of all key stakeholders were represented in our study. Briefly, the public sector organisations included, MoHCDGEC, MSD, President's Office Regional and Local Government and representatives of health facilities. The private sector organisations included, Deloitte Consulting and PricewaterhouseCoopers, Tanzania (as the Local Funding Agency for the Global Fund); while the development partners included, Global Fund, USAID- Global Heath
Table 2 Categories of key informants

\begin{tabular}{llc}
\hline Sector & Category of participant & No \\
\hline Public sector & Policy-maker & 4 \\
& Management & 12 \\
& Frontline health workers & 10 \\
Private sector & Management & 3 \\
Development partners & Management & 7 \\
Civil society & Management & 5 \\
\hline Total & & 41 \\
\hline
\end{tabular}

Supply Chain Programme, United Nations agencies and WHO. Civil society organisations comprised of faithbased organisations and community-based organisations, involved in healthcare delivery in the country.

From the list of organisations identified in the desk review, key informants were identified based on their functions and knowledge of the reform at MSD. In total, we identified 47 participants of which 6 were not able to participate, mainly due to time and logistical constraints. Table 2 provides a breakdown of the different categories of key informants.

The interview process used an interview guide (online supplemental appendix 2), first developed in English and then translated into Swahili, which is the national language in Tanzania. The interview guide was comprehensively pretested by the research team and necessary modifications and adjustments were made before field deployment. The KII approach, which involved in-depth interviews, was used to collect data from the selected participants.

Three researchers, the 3rd, 10th and last authors, all trained in healthcare and with postgraduate training in public health and research methods, lead the data collection effort. To conduct the interview, arrangements were made to secure a 1 hour appointment with the participant, at a suitable venue for a face-to-face interview. Prior to starting the interview, researchers introduced themselves, explaining the objectives of the study and obtained verbal informed consent to proceed with the interview. Participants were made aware that they could stop participating in the interview at any stage without prejudice. The questions in the interview guide served to sign post the conversation and ensured that respondents covered the key aspects of interest in our research. The interviews were recorded using a digital voice recorder and researchers took notes during the interview.

\section{Data analysis}

Qualitative data obtained from interviews was transcribed shortly after the interviews and then analysed manually applying thematic content analysis. The transcripts were read and re-read several times by all the three researchers in order to become familiar with their content. Transcripts were then coded by the three researchers and similar or related codes were categorised under the same thematic 


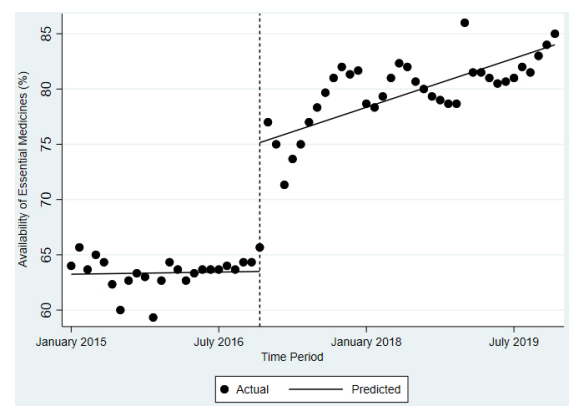

Figure 1 Interrupted time series analysis.

area. We found this approach to be appropriate for semistructured expert interviews as it is used for coding text with a predefined coding system, which can then be refined and complemented with new emerging themes. ${ }^{27}$

\section{RESULTS}

\section{Operational performance}

Average availability of the 312 trace medicines and health commodities at the MSD stores in the preintervention period was $63.5 \%$ (95\% CI $62.6 \%$ to $64.1 \%$ ), but increased to $79.9 \%$ (95\% CI $78.9 \%$ to $81.1 \%$ ) in the postintervention period. Figure 1 shows the ITSA, with actual data points and predicted results, before and after the intervention, divided by the vertical line.

Table 3 shows the regression results using data that is unadjusted for seasonality (A), and data adjusted for seasonality (B). The starting level of availability of health commodities based on unadjusted data was estimated at around $63.1 \%$; but this appeared to increase every month by about $0.03 \%$, until the beginning of the intervention; although the increase was not significant. In the period immediately after the intervention, availability increased significantly by $12.6 \%$ (95\% CI $9.6 \%$ to $15.6 \%$ ), and continued to increase on a monthly basis by $0.2 \%(95 \%$ CI $0.0 \%$ to $0.3 \%$ ) relative to the preintervention trend. Further, the postintervention trajectory indicated that availability significantly increased by $0.2 \%(95 \%$ CI $0.1 \%$ to $0.3 \%$ ) each month.

Using seasonally adjusted data, the starting point of availability of health commodities was estimated at $62.2 \%$. However, availability appeared to increase significantly by $10.0 \%$ (95\% CI $4.8 \%$ to $14.6 \%$ ), in the period immediately after the start of the intervention. Moreover, there was a $0.1 \%(95 \%$ CI $-0.1 \%$ to $-0.3 \%)$ monthly increase relative to the preintervention period, but this was not significant. The postintervention trajectory indicated a monthly increase in availability by $0.2 \%$ (95\% CI $0.1 \%$ to $0.4 \%)$.

Table 4 shows the average annual order fill rates for all medicines and commodities requested at different levels of the health system between 2015 and 2018. On average, the order fill rate from the zones to facilities, dropped from $64.2 \%$ to $55.4 \%$ between the reporting periods 2015/2016 and 2017/2018. Meanwhile, the order fill rate from the central medical warehouse to the zones, reported a $19.4 \%$ decline over the same reporting period. However, table 4, also shows that the integrated logistics system (ILS) and the related delivery of commodities attained consistently high coverage above $90 \%$, over the same period.

\section{Financial performance}

Figure 2 shows that between the financial reporting periods 2014/2015 and 2018/2019, sales increased by $41.2 \%$ while the cost of goods sold (COGS) increased by $60.9 \%$. The gross profit margins remained stable over the same period, showing an improvement of approximately $3.2 \%$ between $2014 / 2015$ and $2018 / 2019$. However, the peak sales were in the period $2017 / 2018$, which registered

Table 3 Coefficients estimated from interrupted time series analysis models

Description

A: Data not controlled for seasonality

$\beta_{0}$ : starting level (baseline) of availability

$\beta_{1:}$ the trajectory of availability until the introduction of the intervention

$\beta_{2}$ : the change in the level of availability in the period immediately following the introduction of the intervention (compared with the counterfactual)

$\beta_{3}$ : the difference between preintervention and postintervention slopes of availability

$\beta_{1}+\beta_{3}$ : the postintervention linear trend of availability

\section{B: Data controlled for seasonality using a cubic spline}

$\beta_{0}$ : starting level (baseline) of availability

$\beta_{1:}$ the trajectory of availability until the introduction of the intervention

$\beta_{2}$ : the change in the level of availability in the period immediately following the introduction of the intervention (compared with the counterfactual)

$\beta_{3}$ : the difference between preintervention and postintervention slopes of availability

$\beta_{1}+\beta_{3}$ : the postintervention linear trend of availability

${ }^{*} \mathrm{P}<0.05,{ }^{\star \star} \mathrm{P}<0.01$. 
Table 4 Annual operational performance

\begin{tabular}{llll}
\hline Measure & $\mathbf{2 0 1 5 / 2 0 1 6}$ & $\mathbf{2 0 1 6 / 2 0 1 7}$ & $\mathbf{2 0 1 7 / 2 0 1 8}$ \\
\hline Units & $\mathbf{( \% )}$ & $\mathbf{( \% )}$ & $\mathbf{( \% )}$ \\
\hline Order fill rate (from zone to facility) & 64.2 & 64.4 & 55.4 \\
Order fill rate (from central stores to zones) & 73.4 & 34.4 & 54.0 \\
ILS delivery coverage & 91.2 & 93.7 & 97.7 \\
\hline
\end{tabular}

ILS, integrated logistics system.

a 56.6\% increase from the 2014/2015 baseline. There was a commensurate increase in COGS of $88.6 \%$ over the same period, with gross margins remaining relatively stable.

A further examination of the annual income statement shown on table 5, indicates that other incomes and grants contributed substantially to the financial position of MSD, with an overall increase of $56.4 \%$ of the reported surplus between 2014/2015 and 2017/2018 financial period. However, in contrast the surplus dropped by $10.6 \%$, when comparing 2014/2015 with 2018/2019. This period of comparison also reported an increase in the total expenses, by $31.5 \%$. According to more granular data from financial reports (not shown), expenses related to employee compensation increased by $38.2 \%$, meanwhile the rental expense reduced by $56.2 \%$ over the same period. Fuel costs reduced by $13.0 \%$, while the insurance expenditure increased by $166.3 \%$. Most of the other expenses remained relatively stable over the financial reporting period.

Table 6 shows the financial ratios related to the performance of MSD. Between 2014/2015 and 2018/2019, the current ratio averaged 1.5. Meanwhile, over the same period, the cash ratio averaged, 0.3 , with the highest being 0.5 reported in the $2016 / 2017$ period. The receivables turnover ratio improved from 1.0 in 2015/2016, to 1.3 in $2018 / 2019$ period, with the highest ratio being 1.6 at $2017 / 2018$. Similarly, the inventory turnover ratio improved from 1.5 in $2015 / 2016$, realising peak performance of 4.8 in the year $2017 / 2018$. This trend was mirrored by the days inventory outstanding, which reported a reduction from 237 days in the year 2015/2016 to 147 days in the year $2018 / 2019$, with peak performance in $2017 / 2018$ at 76 days.

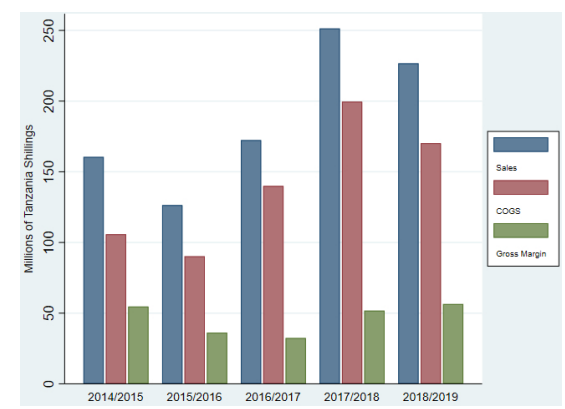

Figure 2 Annual financial reporting. COGS, cost of goods sold.
The net working capital turnover ratio was stable over the 4-year period, averaging 1.9, with the highest performance being 2.7 in $2017 / 2018$. In tandem, the cash to cash cycle was generally high averaging, 227 days over the 4-year period. However, from 2015/2016 to 2017/2018, there was a general reduction in the number of days in the cash-to-cash cycle from 253 days to 170 days, respectively. Other results from the related financial reports (shown in online supplemental appendix 3), indicated that the working capital increased by $35.1 \%$ over the period 2014/2015 and 2017/2018, while the government receivable increased by $50.2 \%$.

\section{Health worker Sentiments}

Table 7 shows some of the key results from the thematic analysis framework applied in assessing the views expressed by different key informants.

\section{Improved access to medicines and health commodities}

Majority of those interviewed acknowledged that the Global Fund support to MSD had been central in improving availability and population access to medicines. This has been attained by ramping up efficiency and reliability of its operations. In addition, respondents in the leadership of MSD revealed that the support had benefited the overall financial position of the organisation.

'There used to be times when we (MSD) were known to have empty stores. You (health facilities managers) could come here and return empty handed (to the health facilities) after traveling for hours. Doctors used to write prescriptions and give patients to go to private pharmacies. But nowadays we are better off, although we (MSD) still have a long way to go. Most of the medicines we need at the (public) facilities are available and even those from private (health facilities) are coming to us.' Participant 1, MSD Central Store Staff

\section{Improved efficiency within the healthcare system}

Majority of the respondents cited the modern warehousing facilities both at the central and zonal levels as good investments that had enabled MSD to attain better visibility and storage of medicines, and other health supplies creating optimal conditions; and thus, enhancing performance. In addition, it was reported by the MSD management personnel that, before the procurement of the new warehouse facilities, MSD used to incur significant rental 
Table 5 Income statement

\begin{tabular}{|c|c|c|c|c|c|}
\hline & $2018 / 2019$ & $2017 / 2018$ & $2016 / 2017$ & $2015 / 2016$ & 2014/2015 \\
\hline Time period & TZS ‘000 & TZS ‘000 & TZS ‘000 & TZS '000 & TZS '000 \\
\hline Sales & 235352238 & 251389265 & 172413432 & 126440444 & 160533362 \\
\hline Gross margin & 33660348 & 51783861 & 32404958 & 36220906 & 54697990 \\
\hline Other incomes and grants & 41792583 & 36180063 & 18448061 & 12325750 & 5974869 \\
\hline Surplus/(deficit) for the period & 5524830 & 9666797 & 7624024 & 6538263 & 6181711 \\
\hline
\end{tabular}

Notes: US\$1=TZS 2300.

expenses from private facilities which were not optimal for the storage of priority medicines and other health commodities.

\begin{abstract}
'The new warehouses have been a game changer! We are now able to store medicines and (health) commodities safely and according to the standards. Here in Dar es Salaam (central store), at times we also used to rent storage from private companies and that was very expensive. Our(MSD) aging fleet used to breakdown often, particularly during the rainy season and needed costly repairs. But now that is a thing of the past!'. Participant 2, MSD Management
\end{abstract}

\section{Improved responsiveness to health system needs}

There was also consensus from both the MSD staff and health facilities respondents that the modern fleet at MSD, had significantly improved the delivery of medicines and health commodities to peripheral health facilities. The delivery times were reported to have significantly reduced and health facilities managers were confident to receive their orders on time, and thus reducing the need for overstocking and resultant expiries. The physical conditions of the health commodities at delivery were also reported to have improved, as a result of better storage and transportation conditions. However, it was noted by some MSD staff at the zonal level, that the available fleet was not optimally used because of the limited number of drivers that had been employed.
'Nowadays, when we need commodities here at the (health) facilities, we can just order from the MSD stores. It is easy to know what they have in storage and we can also easily estimate how much we need for a period of 1-2 months, and they deliver directly to us since they have new vehicles. However, there are times when we make requests for some medicines, and they still don't have them.' Participant 3, Pharmacist, Public Health Facility

Most of those interviewed also reported that training of human resources had been augmented through the Global Fund support and this has been a critical pillar in improving the performance of MSD. Majority of respondents among the MSD staff reported that they were more aware of their roles and responsibility since receiving the necessary training and sensitisation. This awareness was further reinforced by the regular monitoring and evaluation that had been institutionalised through the SMO. MSD senior management respondents pointed out the board level reforms that had been instituted through the Global Fund and USAID support as being critical to the overall strategic leadership and effective management of the organisation.

'The Global Fund supported a major strategic overhaul of MSD. It was a systematic process and really focused on understanding the underlying issues at the organization. It is often easy to identify problems but

\begin{tabular}{|c|c|c|c|c|c|}
\hline Time period & $2018 / 2019$ & $2017 / 2018$ & $2016 / 2017$ & $2015 / 2016$ & $2014 / 2015$ \\
\hline Current ratio & 1.2 & 1.5 & 1.5 & 1.6 & 1.4 \\
\hline Receivables turnover ratio & 1.3 & 1.6 & 1.3 & 1.0 & \\
\hline Inventory turnover ratio & 2.5 & 4.8 & 3.7 & 1.5 & \\
\hline Net working capital turnover ratio & 1.0 & 2.6 & 2.0 & 1.6 & 2.3 \\
\hline Cash-to-cash cycle & 309 & 170 & 177 & 253 & \\
\hline
\end{tabular}


Table 7 Thematic analysis framework

\begin{tabular}{lll}
\hline Codes & Emerging themes & Global themes \\
\hline $\begin{array}{l}\text { Health facilities used to face many stockouts of } \\
\text { essential medicines }\end{array}$ & $\begin{array}{l}\text { Improved management of medicines and } \\
\text { commodities }\end{array}$ & $\begin{array}{l}\text { Improved access to medicines and } \\
\text { health commodities }\end{array}$
\end{tabular}

Limited storage capacity hindered MSD operations

There is an increased portfolio of products available at MSD

Modern fleet of vehicles have improved and expanded Reduction in delivery times to health facilities the reach of MSD

\begin{tabular}{|c|c|c|}
\hline $\begin{array}{l}\text { Training of human resources essential for progress to } \\
\text { be made }\end{array}$ & Satisfied customers across the health system & $\begin{array}{l}\text { Improved responsiveness to health } \\
\text { system needs }\end{array}$ \\
\hline $\begin{array}{l}\text { Effective supervision based on key performance } \\
\text { metrics is important }\end{array}$ & $\begin{array}{l}\text { Better communication between zones and health } \\
\text { facilities }\end{array}$ & \\
\hline $\begin{array}{l}\text { Strategic management office central in tracking } \\
\text { progress }\end{array}$ & $\begin{array}{l}\text { MSD Zones as business units are effective in } \\
\text { meeting health facility needs }\end{array}$ & \\
\hline
\end{tabular}

Tracking progress and getting feedback is important for progress

Data use is important for effective management Improved forecasting and quantification of needs
decisions

Optimal storage conditions have greatly improved MSD operations

MSD can directly procure medicines and commodities from manufacturers

Reduced inventory loss due to wastage and expiries

Improved efficiency within the healthcare system

Cost cutting opportunities due to economies of

scale

Better visibility of medicines and health commodities

across the system

There has been expansion of MSD operations to reach

every corner of the country

There has been a reduction in expenditure on

maintenance of old fleet and leasing of warehouses

\begin{tabular}{ll} 
Global fund has been a strong partner & $\begin{array}{l}\text { Donors and government need to meet their } \\
\text { obligations }\end{array}$ \\
$\begin{array}{ll}\text { Imperative for timely payment to ensure MSD } \\
\text { operations are sustainable }\end{array}$ & $\begin{array}{l}\text { Improvements in revenue generation capacity } \\
\text { towards sustainable operations }\end{array}$ \\
\hline
\end{tabular}

Need for other donors to support the MSD operations

MSD, Medical Stores Department.

tackling them is another issue altogether and I think SMO was key. They (Global Fund) ensured that the solution was owned by the Tanzanians rather than the donors'. Participant 4, PORALG

\section{Sustainability of the gains important}

Many of the respondents agreed that quality data were essential for the smooth functioning of procurement and supplychain systems. Therefore, they cited the investments in the information management systems implemented through the Global Fund support as having played a key role in improving performance at the organisation. The MSD management revealed that through better collection and use of highquality data, decision makers at various levels were empowered to effectively quantify and forecast needs as well as have better visibility of distribution systems.

At the zonal and facility levels, the investment in information management systems had reportedly allowed for better visibility of products and seamless ordering of medicines and health commodities, from higher levels or redistribution whenever necessary. Many respondents concurred that this situation had led to reduced expiries and wastage of essential medicines and other health commodities, which previously were common occurrence.

'According to me, the investments in modern warehouse(s) and better data for monitoring (health) commodities go hand in hand. Now, we have better visibility of commodities at various levels, from central to the zones and up to the facilities. We are now able to manage our inventory better and avoid wastage and expiries.'

Participant 5, MSD Zone Manager

According to the MSD management, its financial position had been significantly strengthened by the fact that Global Fund regularly paid $6 \%$ of the cost of vertical programme's products it channelled through MSD's distribution network. This formed a substantial revenue stream that is critical in ensuring the financial sustainability of MSD. However, it was also reported that other development partners that were channelling health commodities through the MSD distribution 
network were not making similar commitments, a situation that put the organisation's sustainability at risk. Similarly, the government had accumulated significant receivables to MSD, if not fully settled on time, this would significantly disrupt the smooth operations at the organisation.

\section{DISCUSSION}

Our study substantially contributes to the literature on strengthening health systems in low-income and middleincome countries, with specific emphasis on procurement and supply-chain systems. This is an important subject of inquiry considering that many countries are still grappling with health service delivery gaps, that could be directly or indirectly attributed to dysfunctional procurement and supply-chain systems. ${ }^{16-20}$ As Garcia $e t a l^{28}$ point out, effectively tracking the levels of access to medicines is fundamentally vital for any health system that aims to meet population health goals.

In interpreting the results presented in this article, we are cognisant that we have based our findings on a limited period of observation and a limited set of indicators. Further, our study was not conceptualised before the onset of the intervention reported here, and therefore, no specific steps were taken to develop an appropriate research design and data collection strategy to support a more rigorous assessment. Instead, we have had to rely on available secondary programmatic data and interviews with key personnel that could be affected by various forms of bias. ${ }^{29}$ We are also aware that our study could be subject to confounding relationships with other concurrent interventions which could complicate our attribution of impact to specific interventions. However, we have made efforts to mitigate for this, by employing a mixedmethods approach, using both quantitative and qualitative research methods, and triangulating multiple data sources into a consistent analytical framework.

There is evidence that the Global Fund supported reform resulted in positive improvements in the overall performance at MSD. Availability of essential medicines and other health commodities increased, indicating improved capacity to meet demands emanating from the health facilities. This could be attributed to several factors related to the Global Fund support; notable ones being, better quantification and forecasting capabilities (due to availability of data through EPICOR and training of staff); improved warehousing capacity to hold a wide portfolio of products and direct delivery to facilities through a modern fleet.

There are many studies pointing to the importance of such interventions as envisaged in the strategic reforms in boosting availability of health commodities. ${ }^{21273031}$ For instance, Modisakeng $e t a l^{32}$ concluded that in order to tackle medicines shortages, there was need for ongoing support to provincial pharmacies in South Africa for better contract management and improved data systems to aid inventory management. Similarly, Meyer $e t a b^{33}$ observed that there were a number of initiatives surrounding the availability and access to medicines in the public system in South Africa; many of which focused on early warning systems for the supply of medicines, improvements in data for quantification and forecasting as well as effective contract management.

It is sensible to conclude that improvements in availability of commodities could not have been possible without better management practices at all levels. Therefore, it can be inferred that the newly formed SMO, was impactful in driving institutional reforms such as strengthening the Board oversight capacity, human resource training and supervision to drive operations and fiscal management. More specifically, SMO was critical in the institutionalisation of the culture of performance assessment and advocating for the adoption of information management system improvements, all which were critical for the effective functioning of MSD. ${ }^{9}$

Increased and modern storage capacity allowed MSD to procure and safely store an expanded portfolio of products. The expanded tracer list was indicative that MSD was procuring a broad range of medicines and health commodities covering different therapeutic areas. ${ }^{8}$ Carrying an expanded portfolio of medicines allows the Tanzania health system to respond better to a wide range of healthcare needs in line with the universal health coverage aspirations, in the backdrop of an evolving disease burden. ${ }^{34}$ As Godman $e t$ $a l^{35}$ point out in a multicountry review of activities to aimed at tackling the rising epidemic of type 2 diabetes mellitus in Africa; more needs to be done (particularly in terms of access to medicines) in order to improve the management of patients with diabetes.

Still, to sustainably procure an expanded portfolio of commodities and ensure high levels of availability of essential commodities requires a strong financial position to negotiate preferential procurement terms directly from wholesalers and/or manufacturers. It is our assessment that the apparent strengthening of MSD financial position, as shown by increasing sales could have played a role in this trend. This observed trend is further supported by the increasing GOGS in successive years, indicating that MSD was procuring more to meet healthcare needs of the country. However, it is of concern that despite increasing sales, the order fill rates from both the headquarters to the zones and the zones to health facilities, had not shown significant improvement. This means that despite expanding the tracer list, many of the medicines and health commodities needed by the health facilities are still not adequately served.

Through an expanded ILS, personnel at the central and zonal levels have improved visibility of the current needs at respective health facilities and are empowered to rationalise the distribution of products to meet the needs on the ground. With improved operational performance, the financial position of MSD showed a growth trajectory in terms of sales. The increased revenues could be attributed to several factors including, a steady revenue stream from the Global Fund service fees and an improved warehousing infrastructure which allowed MSD to procure and store an extended range of products for sale. In addition, the distribution network to reach more health facilities had been strengthened through the modern fleet, and this translated into more sales. The Government of Tanzania had also increased its allocation for procurement of health products, as a result of the advocacy 
efforts by various stakeholders and its commitments to meet global health goals. ${ }^{379}$

Despite the MSD being a non-profit organisation, an improvement in income surplus is a positive indication towards achieving financial sustainability. However, despite earlier increases of income surplus, the later reporting period reported a marked decline which could be partly driven by an overall increase in MSD expenses. This was even though a deeper examination revealed a relative reduction in key expense items like rent for warehousing and maintenance for ageing equipment and vehicles. The current ratio which underscores the liquidity position of MSD to meet its shortterm financial obligations was generally favourable, with a gradual improvement over time. This could be attributed to the measures implemented at MSD such as implementing a cash and carry policy and efforts to collect overdue receivables from key accounts, with a varying level of success. ${ }^{9}$

Despite the improvements in the successive current ratios, the more stringent liquidity measure, cash ratio was generally, low across the years. A cash ratio of between 0.5 and 1 is considered good, but in the case of MSD, the average was 0.31, indicating that MSD might not be able to sufficiently meet its short-term financial obligations, using cash and cash equivalents at its disposal. This was a significant risk to MSD, given the nature of its operations, where rapid procurement might be needed to respond to emergencies or steady commitments for prevalent health needs.

The receivable turnover ratio was low despite the marginal increase over the years; indicating that MSD was not quickly converting the credit sales into cash to support its operations. In fact, the increasing government receivable, which increased by more than $50 \%$ between 2014/2015 and 2017/2018 was a major risk to MSD's financial solvency and overall sustainability. Another key pointer to this trend was the long cash to cash cycle, which despite an improving trend, was still significant. On average it took 227 days to convert the inventory held by MSD into cash. It was very clear that a significant portion of this cash value was locked within the ballooning government receivable.

The improvements in inventory turnover ratios over the years showed better capacity to effectively manage inventory, and hence reduction in potential losses due to wastage, obsolesce and expiries. Better warehousing, transportation, enhanced product visibility, responsive and empowered zonal management teams, among others, were all critical to these observed progress. But still, it must be clarified that, despite the improvements in inventory management, more still needed to be done. On average, it took MSD 140 days, to sell its inventory, which led to significant holding costs, eroding the bottom line.

Overall, the donor community and the government are still central to the future sustainability of MSD. Therefore, in order to strengthen MSD's financial position, development partners and other stakeholders including government, which distribute medicines and health commodities through the MSD channels should be cognisant of the cost implications and expenses associated with these operational activities. In addition, all stakeholders must undertake to pay their fair share of the related costs and expenses owed to MSD in a timely manner in order to avoid interruptions of critical operations.

Ultimately, for MSD to effectively meet its obligations and deliver on its mandate, it must be led by an accountable team focused on continually improving its performance. The existing governance framework comprising of an independent board staffed by high calibre professionals and an experienced management team at the helm of MSD provides an opportunity for further transformation. This will sustain the momentum generated by the reform process and enable MSD to become an exemplar self-sustaining organisation for others to emulate.

\section{CONCLUSIONS}

In summary, there is clear evidence that the Global Fund supported reforms at MSD yielded the desired impact and are on track to achieving the performance and sustainability objectives. However, there are still many risks that could derail this trajectory and should be anticipated and adequately addressed. The recent onset of the COVID-19 pandemic is one such emergency that has been characterised by disruptions in procurement and supply of essential health commodities across countries, and Tanzania was no exception. Clearly, the pandemic has underscored the need for multistakeholder measures to address global procurement and supply-chain challenges ensure minimal disruptions in service delivery. $^{36} 37$

Therefore, importance of an effective procurement and supply-chain system to support health service delivery cannot be overstated. It is a critical ingredient to make progress towards universal health coverage. ${ }^{1215-19}$ The Tanzania MSD example demonstrates that in order to build effective procurement and supply-chain systems, sustained and multifaceted support is necessary as opposed to piecemeal and isolated undertakings. ${ }^{1} 278$ Effective supportive measures need to involve all the key health system stakeholders, including those involved in the financing, planning and implementation of health programmes. ${ }^{12}$

Correction notice The article title has been corrected since it was published. Twitter Tom Achoki @tachoki

Acknowledgements We acknowledge The Global Fund to Fight Aids, Tuberculosis and Malaria for facilitating the study's data collection through its Tanzania Local Fund Agent, Price Waterhouse Coopers. The coauthors who were employees of the participating organisations that is, the Global Fund and MSD did not draw any financial assistance, while the coauthors TA, ED and RS who were consultants received a per diem. Further, we appreciate the participants from the different organisations that were respondents to the interviews. More specifically, we appreciate the facilitation support from Pascal Pastory, Salome Mallamia and Bwekwaso Tabura, all from MSD.

Contributors TA, LM, PG and SP conceptualised and designed the study. TA, RS, NM and ED carried out data collection and analysis. TA and PG drafted the manuscript and LM, SP, SA, RI, RS, NM, TP, SMM, AL and LRB did the critical revisions of the manuscript. All authors read and approved the final manuscript.

Funding The authors have not declared a specific grant for this research from any funding agency in the public, commercial or not-for-profit sectors.

Competing interests PG, LM, SP, SA, RI and TP declare that they are full-time employees of The Global Fund to Fight AIDs, Tuberculosis and Malaria. NM, SMM 
and LRB declare that they are full-time employees of the Tanzania Medical Stores Department.

\section{Patient consent for publication Not required.}

Ethics approval Relevant permissions and authorisation to conduct this research were sought and obtained from MSD and MoHCDGEC. The data collection process ensured that all participants fully understood the objectives of the study and consented verbally to provide the required information.

Provenance and peer review Not commissioned; externally peer reviewed.

Data availability statement Data are available on reasonable request. Deidentified data from the key informant interviews, reports and secondary datasets may be made available by the authors on request; and with written permission from the Tanzania MSD and MoHCDGEC.

Supplemental material This content has been supplied by the author(s). It has not been vetted by BMJ Publishing Group Limited (BMJ) and may not have been peer-reviewed. Any opinions or recommendations discussed are solely those of the author(s) and are not endorsed by BMJ. BMJ disclaims all liability and responsibility arising from any reliance placed on the content. Where the content includes any translated material, BMJ does not warrant the accuracy and reliability of the translations (including but not limited to local regulations, clinical guidelines, terminology, drug names and drug dosages), and is not responsible for any error and/or omissions arising from translation and adaptation or otherwise.

Open access This is an open access article distributed in accordance with the Creative Commons Attribution Non Commercial (CC BY-NC 4.0) license, which permits others to distribute, remix, adapt, build upon this work non-commercially, and license their derivative works on different terms, provided the original work is properly cited, appropriate credit is given, any changes made indicated, and the use is non-commercial. See: http://creativecommons.org/licenses/by-nc/4.0/.

\section{ORCID iD}

Tom Achoki http://orcid.org/0000-0001-6309-8904

\section{REFERENCES}

1 WHO. Everybody's business: strengthening health systems to improve health outcomes: WHO's framework for action. Geneva, Switzerland: World Health Organization, 2007.

2 WHO. The world health report: health systems financing: the path to universal coverage. Geneva, Switzerland: World Health Organization, 2010.

3 Ministry of Health. Community development, gender, elderly and children. The National health policy, 2017. Available: www.tzdpg.or.tz

4 Ifakara Health Institute $(\mathrm{IHI})$ and Ministry of Health and Social Welfare (MOHSW). Tanzania service availability and readiness assessment (SARA) 2012: final report. Dar es Salaam: IHI, 2013.

$5 \mathrm{MOHSW}$. Mid term review of the health sector strategic plan III, 2009-2015. Dar es Salaam, United Republic of Tanzania: MOHSW, 2013.

6 MOHSW. Mid term analytical review of the health sector strategic plan III. Dar es Salaam, United Republic of Tanzania: MOHSW, 2013.

7 MOHSW. Health sector strategic plan July 2015 - June 2020. (HSSP IV): reaching all households with quality health care. Dar es Salaam, United Republic of Tanzania: MOHSW, 2015.

8 Ministry of Health. Community development, gender, elderly and children. In: Strategic and action plan for the prevention and control of non-communicable diseases in Tanzania 2016-2020. Dar es Salaam, Tanzania, 2016

9 Medical Stores Department. Medium term strategic plan II 2017 -2020. Dar es Salaam, United Republic of Tanzania: MOHSW, 2020.

10 Mori AT, Owenya J. Stock-outs of antiretroviral drugs and coping strategies used to prevent changes in treatment regimens in Kinondoni district, Tanzania: a cross-sectional study. J Pharm Policy Pract 2014;7:3

11 Deloitte, Global Fund and MSD. Strategic review of the medical stores department of Tanzania: the journey to efficiency. Dar es Salaam, Tanzania, 2016.

12 Deloitte and Global Fund. Organizational transformation of MSD Tanzania: project final report. Dar es Salaam, Tanzania, 2017.
13 Deloitte and MSD. Leading with purpose: board chapter quality assurance review report. Dar es Salaam, Tanzania, 2016.

14 Deloitte and MSD. Target transportation business Model- return cargo. Dar es Salaam, Tanzania, 2018.

15 Global Fund. Audit report: the global fund's in-country supply chain processes. Geneva, Switzerland, 2017.

16 Global Fund. Guide to global fund policies on procurement and supply management ofHealth products. Geneva, Switzerland, 2018.

17 Cameron A, Ewen M, Ross-Degnan D, et al. Medicine prices, availability, and affordability in 36 developing and middle-income countries: a secondary analysis. Lancet 2009;373:240-9.

18 Godman B, Basu D, Pillay Y, et al. Ongoing and planned activities to improve the management of patients with type 1 diabetes across Africa; implications for the future. Hosp Pract 2020;48:51-67.

19 Bigdeli M, Jacobs B, Tomson G, et al. Access to medicines from a health system perspective. Health Policy Plan 2013;28:692-704.

20 Ewen M, Zweekhorst M, Regeer B, et al. Baseline assessment of who's target for both availability and affordability of essential medicines to treat non-communicable diseases. PLoS One 2017;12:e0171284.

21 Mackintosh M, Tibandebage P, Karimi Njeru M, et al. Rethinking health sector procurement as developmental linkages in East Africa. Soc Sci Med 2018;200:182-9.

22 Global Fund. The global fund strategy 2017-2022, investing to end epidemics. Geneva, Switzerland, 2019.

23 Linden A. Conducting interrupted time-series analysis for single- and multiple-group comparisons. Stata J 2015;15:480-500.

24 Bhaskaran K, Gasparrini A, Hajat S, et al. Time series regression studies in environmental epidemiology. Int J Epidemiol 2013;42:1187-95.

25 Byrne M. Sampling for qualitative research. Aorn J 2001;73:494-8.

26 Biernacki P, Waldorf D. Snowball sampling: problems and techniques of chain referral sampling. Sociol Methods Res 1981;10:141-63.

27 Achoki T, Lesego A. The imperative for systems thinking to promote access to medicines, efficient delivery, and cost-effectiveness when implementing health financing reforms: a qualitative study. Int $J$ Equity Health 2017;16:53.

28 Garcia MM, Barbosa MM, Silva RM, et al. Indicator of access to medicines in relation to the multiple dimensions of access. $J$ Comp Eff Res 2019;8:1027-41.

29 Prada-Ramallal G, Takkouche B, Figueiras A. Bias in pharmacoepidemiologic studies using secondary health care databases: a scoping review. BMC Med Res Methodol 2019;19:53.

30 Kagaruki G, Kimaro H, Mboera L. Factors affecting utilization of evidence based health information system for effective supply chain of essential medicine in Tanzania: a case study from Mbeya region. $J$ Health Inform Dev Ctries 2013;7.

31 Ripin DJ, Jamieson D, Meyers A, et al. Antiretroviral procurement and supply chain management. Antivir Ther 2014;19:79-89.

32 Modisakeng C, Matlala M, Godman B, et al. Medicine shortages and challenges with the procurement process among public sector hospitals in South Africa; findings and implications. BMC Health Serv Res 2020;20:234.

33 Meyer JC, Schellack N, Stokes J, et al. Ongoing initiatives to improve the quality and efficiency of medicine use within the public healthcare system in South Africa; a preliminary study. Front Pharmacol 2017;8:751

34 Gouda HN, Charlson F, Sorsdahl K, et al. Burden of noncommunicable diseases in sub-Saharan Africa, 1990-2017: results from the global burden of disease study 2017. Lancet Glob Health 2019:7:e1375-87.

35 Godman B, Basu D, Pillay Y, et al. Review of ongoing activities and challenges to improve the care of patients with type 2 diabetes across Africa and the implications for the future. Front Pharmacol 2020;11:108.

36 Queiroz MM, Ivanov D, Dolgui A, et al. Impacts of epidemic outbreaks on supply chains: mapping a research agenda amid the COVID-19 pandemic through a structured literature review. Ann Oper Res 2020:1-38.

37 Gereffi G. What does the COVID-19 pandemic teach us about global value chains? the case of medical supplies. J Int Bus Policy 2020;3:287-301.

38 Chee G, Pielemeier N, Lion A, et al. Why differentiating between health system support and health system strengthening is needed. Int J Health Plann Manage 2013;28:85-94. 